\title{
Extradural haematoma at the vertex
}

\author{
F. COLUMELLA, G. GAIST, G. PIAZZA, AND T. CARAFFA \\ From the Department of Neurosurgery, Ospedale Maggiore, Bologna, Italy
}

The impression one gathers from the literature on epidural effusions at the vertex is that knowledge of this haematoma is still evolving. For this reason we thought it worthwhile to review the cases reported in the available literature, after discussing a case of our own.

\section{CASE REPORT}

B.R., a male aged 27, accidentally fell off his motor cycle on 30 July 1959 , striking the left parietal region against the ground. He suffered no open wounds, did not lose consciousness, and got up unaided, but complained immediately of nausea and diffuse headache. He was admitted to the Neurosurgical Department, Ospedale Maggiore Bologna, Italy, about eight hours after the accident.

On admission he appeared to be in acute distress because of headache, and rather drowsy. However he was oriented, though not very cooperative. The pulse rate was $80 / \mathrm{min}$ and rhythmic; blood pressure $130 / 90$ mmHg.; respiratory rate was $20 / \mathrm{min}$. There was slight nuchal rigidity. Deep tendon reflexes were uniformly depressed. The remainder of the neurological examination was negative. There was nothing relevant in his family or personal history.

Plain radiographs of the skull showed a linear fracture (Fig. 1), with widened margins, without depression, running parallel to the sagittal suture in the upper part of the right parietal bone, crossing the coronal suture and extending into the right parasagittal portion of the frontal bone. The widening of the fracture line appeared to be greater in its posterior part, reaching here a width of $2-3 \mathrm{~mm}$.

CLINICAL COURSE 1 August 1959 The patient was more alert, but still complaining of excruciating headache. Slight nuchal rigidity was still present. There was no other change in his condition. Investigations showed the following results: $\mathrm{RBC} 4,700,000 / \mathrm{cu} . \mathrm{mm} ; \mathrm{Hb} .84 \%$;WBC $12,000 /$ cu.mm; neutrophils 78 ; eosinophils 2 ; lymphocytes 18; myelocytes $2 \%$. Blood urea nitrogen $30 \mathrm{mg} /$ $100 \mathrm{ml}$.; fasting blood sugar $98 \mathrm{mg} / 100 \mathrm{ml}$.; Wassermann test negative. Electroencephalography showed an asynchronous record. There was occipital activity with random $9 \mathrm{c} / \mathrm{s}$ waves, $50 \mu \mathrm{v}$ bilaterally. On all leads, but mainly in the frontal ones, were bursts of 2-3 c/s, 90-100 $\mu \nu$ waves. It was impossible to assess the effect of hyperventilation because of the patient's lack of cooperation.

2 August The patient was afebrile, but still complaining of diffuse headache, unrelieved by rest or analgesics.
3 August The patient was afebrile. Because of the persistence of headache, right carotid angiography was performed in spite of the lack of neurological signs. The films (Fig. 2a, b) showed an avascular area at the vertex.

4 August The patient was afebrile and still complaining of severe and continuous headache.

5 August The patient was afebrile, with a constant headache. He vomited for the first time.

7 August Contralateral angiography showed neither increase nor reduction of the avascular area at the vertex, and also disclosed a downward dislocation of the meningeal vessels in the area of the haematoma (Fig. 3).

OPERATION General anaesthesia was induced with endotracheal intubation, $\mathrm{N}_{2} \mathrm{O}, \mathrm{O}_{2}$ and intravenous pentothal, in addition to local anaesthesia with $1 \%$ xylocaine and $0.001 \%$ adrenaline. A right parasagittal

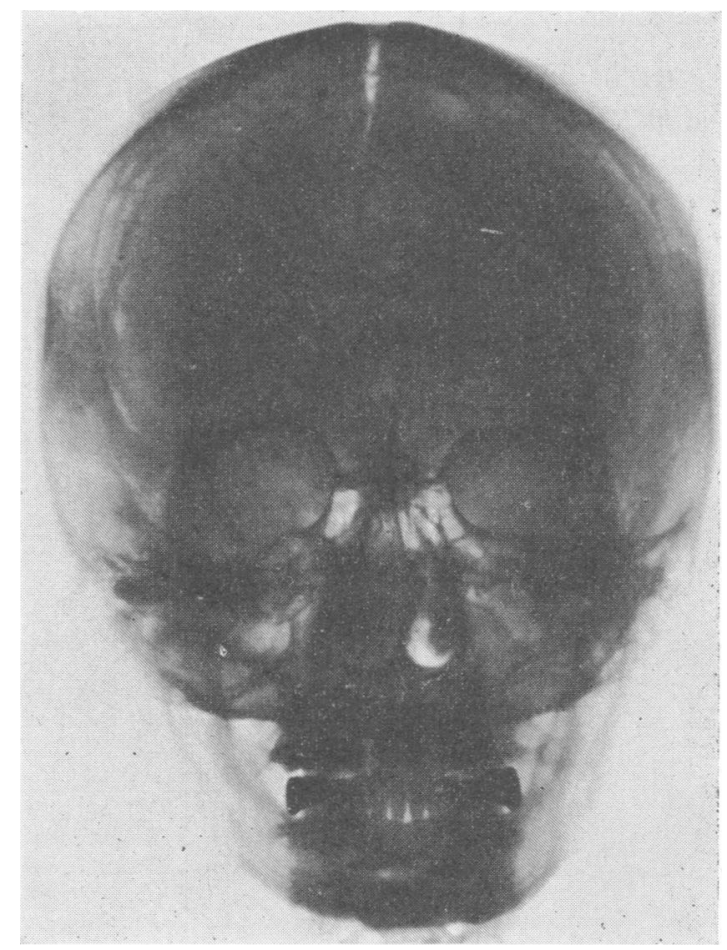

FIG. 1. Plain radiograph of the skull showing fracture line. 
FIG. 2. Right carotidogram in the lateral $(a)$ and in the frontal (b) projections, showing avascular area at the vertex.

fronto-parietal flap crossing the midline for about $2 \mathrm{~cm}$ was turned. There was diffuse bleeding from periosteum and bone. On raising the bone flap-which, because of the fracture crossing it obliquely, consisted of two sections held together by periosteum-a large collection of clotted blood was found, displacing the dura downwards and compressing the brain and the longitudinal sinus. The inner surface of the bone flap was covered with

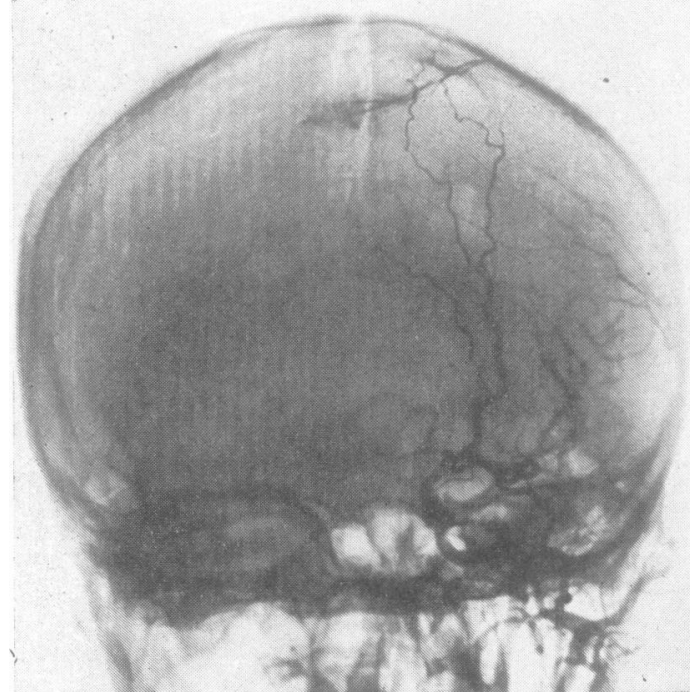

FIG. 3. Left carotidogram (four days' later) showing the avascular area at the vertex to be unchanged; the meningeal vessels are also injected and show a downward dislocation, thus proving the haematoma to be extradural. blood clots and their removal was followed by oozing which was easily controlled by means of bone wax. The $\vec{v}$ haematoma was extradural, bilateral, mainly situated 응 the right frontoparietal area and extending about $4 \mathrm{cs}$ lateral to the longitudinal sinus. To the left of the longitudinal sinus the effusion was smaller, stripping the dura for about $2 \mathrm{~cm}$. The thickness of the haematoma wis about $3 \mathrm{~cm}$ at its centre, gradually becoming thinner $\stackrel{\infty}{+}$ toward the periphery. The extension of the haematoma啇 $\vec{\theta}$ its sagittal plane was about $10 \mathrm{~cm}$, of which about 2 cศ was in front of the coronal suture. The clot was removed by suction. No tear in the superior longitudinal sinus was revealed. Even after the removal of the haematoma the dura appeared to be under tension, so that it was $\bar{\partial}$ incised and a spurt of about $20 \mathrm{ml}$. of clear xanthochromic fluid escaped from the subdural space through the $\mathbb{D}$ incision. The underlying brain appeared to be highly hyperaemic, still showing the imprint of the haematoma; however there were no subpial or subarachnoid haemorrhages, petechiae, or cerebral, meningeal, or vascular lacerations. The inner surface of the dura appeared greenish-grey, probably because of haemosiderin infiltration. Closure was performed in the usual fashion.

As soon as the patient woke from the anaesthesia he noticed that his headache had disappeared. The postoperative course was uneventful and he was discharged 14 days after the operation, at which time neurological examination was completely normal.

\section{COMMENT}

To sum up the case, attention is drawn to the following features:

1. The haematoma was associated with a small $\mathbb{O}$ subdural hygroma. 
2. The chief symptom was headache, which was uninterrupted, diffuse, severe, and unrelieved by analgesics until the moment (eighth day after injury) when the haematoma was removed. The headache had completely disappeared when the patient awoke from the operation anaesthesia.

3. Contrary to what would be expected from the location of the blood collection, from its considerable size, and from the downward displacement of the brain, there were no motor or sensory deficits.

4. Pre-operative angiograms, taken on the fourth and on the eighth day after injury, showed no quantitative or qualitative changes.

5. At the operation table the fracture line was seen to coincide with the centre of the blood extravasation. The longitudinal sinus and the adjacent dura did not appear to be torn. It may be concluded that the origin of the haematoma must have been a haemorrhage from the bone fracture, or from the dural separation, or from both.

\section{REVIEW OF THE LITERATURE}

The earliest record of an epidural haematoma at the vertex is probably that of Guthrie: in 1862 he reported the case of a soldier who had suffered a head injury falling off his horse and developed such an intracranial lesion.

Other haematomas stripping the sagittal sinus from the inner table of the skull were described by Reichert and Morissey (1941) and by Raaf (1948). A colour plate depicting this lesion was included in Rowbotham's Acute Injuries of the Head (1949).

The first angiographic details of epidural haematomas at the vertex begin to appear in 1948 (see Figs. 69d and 69f of Wickbom's monograph, 1948). However, the author did not think that this lesion had to be separated from other intracranial extracerebral effusions. Another case was reported in 1952 by Brodin (as a personal communication from Frysholm).

Another angiographic picture of epidural haematoma at the vertex is shown in Fig. 4 in the paper by Wertheimer, Levy, Laplas, and Tusini (1958) on the angiographic features of traumatic intracranial expanding lesions. It is the lateral view of an angiogram showing a biconvex avascular area at the vault, its centre underlying the vertex.

In 1959 Columella, Delzanno, and Nicola published a clinical and radiological study of epidural haematoma at the vertex, reporting five personal cases, four of which were studied with angiography, and one with pneumoencephalography. These authors were the first to separate epidural haematomas at the vertex from other extradural effusions on the basis of (1) clinical signs (headache as chief complaint); (2) the angiographic picture (avascular area with separation of the superior longitudinal sinus from the inner table of the skull); (3) operative peculiarities (impossibility of locating or evacuating the haematoma through standard exploratory burrholes); and (4) prognosis (favourable).

They proposed that epidural haematomas at the vertex be classified separately among rare or atypical extradural effusions.

These views were shared by D'Andrea and Conforti (1959) who, shortly after, contributed two cases of their own with good angiographic documentation.

During the same year Hooper (1959), in a very extensive article, divided extradural haematomas into four groups: "(1) extradural haemorrhages of the anterior fossa; (2) extradural haemorrhages of the middle fossa; (3) parasagittal haematomas; (4) posterior fossa haematomas.'

Group 3 (parasagittal haematomas) seems to coincide with the lesions described by Columella et al. (1959) on the basis of the anatomical, diagnostic, prognostic, and therapeutic features, while the clinical findings seem to differ because of the more frequent and prominent pyramidal signs, and because in Hooper's patients (Hooper, 1959) the chief complaint of Columella's cases (Columella et al., 1959), headache, is absent. However Hooper (1959) did not classify parasagittal haematomas separately, as all he stated, in addition to a simple description of his five cases, was:

\begin{abstract}
'Haematoma occurred in the parasagittal region five times. There was no distinct relationship between the nature of the accident and the occurrence of the haemorrhage in this situation, but it was observed that there was always some local sign of injury in the parasagittal region. The rate of development of the clinical syndrome was very variable, but pyramidal signs and pupillary inequality appeared more constantly, being present in four out of five cases encountered. No patient in this group died.'
\end{abstract}

Tiwisina and Stäcker (1959), on writing about the importance of angiography in acute cerebral injuries, reported one case of 'epidural parietal parasagittal haematoma' in which the venous phase of the angiography revealed a separation of the longitudinal sinus from the skull vault. In the plate they published (Fig. 1, p. 345) the parasagittal bridging veins also showed downward displacement in the region of the vertex.

Pecker, Javalet, and Stabert (1959), in a paper also stressing the importance of carotid angiography in the evaluation of acute head injuries, published venous lateral (Fig. 15, p. 632) and half-axial (Fig. 16, p. 632) films of a case of 'parasagittal extradural haematoma'. They stated that 'the lateral view shows 
stripping of the superior longitudinal sinus at the level of a fracture line involving the coronal suture'. This haematoma consisted only of 'a few clots' which certainly would not have been found at the operating table without previous angiographic localization. In the same paper, in the paragraph ' $L$ 'artériographie faite par principle chez un traumatisé qui ne s'amèliore pas', their second case is reportedthat of an epileptic patient who, a short but unspecified time after a head injury following a seizure, presented the problem of differential diagnosis between haematoma and intracranial tumour, as he was found to have papilloedema in addition to a right hemiplegia. This was a haematoma, whether sub- or extra-dural is not specified, as the illustrations of this case consist only of the lateral and halfaxial carotid arteriograms in the arterial phase. In the first (Fig. 18, p. 633) all the cortical arteries are pushed away from the inner table of the skull, thus outlining a large posterior parietal biconvex avascular area with a maximum thickness of over $5 \mathrm{~cm}$, while the half-axial view (Fig. 19, p. 633) shows only the lack of displacement of the anterior cerebral artery and of its branches. All this coincides with the features described by Columella et al. (1959) as peculiar to epidural haematomas at the vertex: however the lack of radiographs in the venous phase does not allow this case to be ascribed with certainty to epidural haematomas at the vertex.

Lindgren (1960), in his monograph on acute head injuries, states:

\footnotetext{
'Another patient had an extradural haematoma $(1 \mathrm{~cm}$ deep) above the superior longitudinal sinus, and was not operated upon. The angiograms two months later showed normal conditions and the main neurological symptom was a right-sided paresis, most marked in the arm: the patient was reported in the group of the non-expansive focal contusions.'
}

In their paper on 125 epidural haematomas McKissock, Taylor, Bloom, and Till (1960) include two cases (out of the only six studied with angiography) in which the sagittal sinus was displaced downwards.

Alexander (1961) thoroughly described four cases of epidural haematomas at the vertex. These cases on the whole present clinical pictures similar to those described by Columella et al. (1959).

In $1963 \mathrm{Da}$ Pian, Benati, Bricolo, Tomasi, Perbellini, and Dalle Ore, reported four cases of haematoma at the vertex out of 30 extradural effusions. Both in the lateral and in the anteroposterior view (Figs. 1 and 2, p. 672) of their first case it is possible to see a thin layer of contrast partially outlining the lower border of an avascular biconvex area. In their second case the authors report that the avascular image was semilunar. In their third case there was a compound skull fracture $\mathbb{D}$ at the vertex with laceration of the underlying dura and of a cortical vein, with cerebral contusion and $\stackrel{\oplus}{C}$ with depression of a bone fragment accompaniedô by a small haematoma. In their fourth patient the diagnosis of extradural haematoma at the vertex was made on clinical signs only, which consisted of $\frac{\overrightarrow{0}}{\mathrm{~g}}$. intense headache of many days' duration in a patient with a midline coronal linear fracture who eventually made a spontaneous recovery. In all these $\overrightarrow{\overrightarrow{\vec{D}}}$ patients there was a full thickness fracture of the 0 vault over the middle third of the superior longi-듬 tudinal sinus.

The patient of Stevenson, Brown, and Hoyt (1964) was a 35-year-old man who sustained a bi-parietal fracture across the sagittal suture in a fall off a box- ${ }^{\infty}$ car. Carotidography showed 'inferior displacement $\vec{\circ}$ of the pericallosal arteries in the arterial phase and $\vec{\overrightarrow{ }}$ inferior displacement of the superior sagittal sinus $\stackrel{\omega}{\sigma}$ from the inner table of the skull'. At the operation an epidural haematoma $0.5 \mathrm{~cm}$ in thickness was? removed through four burr-holes placed sym- $\omega$ metrically over the vertex. Among the bibliographical is references cited by these authors we found, include $\omega$ as epidural haematoma interposed between the $\vec{v}$ superior sagittal sinus and the inner table of the skuit, the case reported by Da Rocha-Melo and Resenge (1959). We do not think this type of haematoma cam $?$ be termed 'at the vertex', even though with its edgecte it can strip the sagittal sinus. Analysis of the angiog graphy (Figs. 3, 4, 5, pp. 167-168) shows that the epidural haematoma is not of the type described by $\varnothing_{\infty}$ Columella et al. (1959) and by Alexander (1961) and termed 'at the vertex', but is instead a temporoparietal haematoma, which, in its extension toward the midline, reaches the superior sagittal sinus, displacing it slightly downward. Therefore this haema- $\frac{\square}{\Phi}$ toma should be termed 'parasagittal' and not 'at the $\stackrel{2}{\Rightarrow}$ vertex'. In addition, this haematoma was secondary to a temporal fracture and the angiograms showed upward displacement of the Sylvian vessels. This last element can be considered the main point in the differential diagnosis. The haematoma was eventually removed through a temporo-parietal bone flap.

Also in 1964 Iwata reported four cases of 'sagittal sinus haematomas' which he found in his series of $\delta$ 40 intracranial haematomas operated on in a fiveyear period.

Schechter (1966) published the phlebogram (Fig. D XIV-1) of a case of epidural haematoma with downward displacement of the sagittal sinus.

In reviewing the findings peculiar to epidural $\mathcal{N}$ haematomas at the vertex, it can be observed that $N$ the most frequent one is a fracture line, usually $\underset{\omega}{N}$ 
linear and simple, rarely depressed. The fracture line often intersects the sagittal suture in the region of the haematoma.

In most, but not all, of the cases in which the sequence of the symptoms is described, a lucid interval is found to be present, lasting from a few hours (Alexander, 1961) to five weeks (Stevenson et al., 1964). There are cases (Columella et al., 1959; Da Pian et al., 1963) with temporary loss of consciousness at the onset followed only by a severe intractable headache. It is for this symptom that neuroradiological studies were performed, thus allowing detection of the presence of the haematoma. The most prominent symptom in conscious patients was the headache, present in all cases. It was very severe, persistent, and unrelieved by analgesics. This headache can be explained on the basis of direct irritation of the haematoma on the dura, which around the longitudinal sinus is particularly rich in sensory terminations, or it may be secondary to intracranial hypertension. This second hypothesis can be supported by the third patient of Columella et al. (1959) in whom headache was temporarily relieved after a spinal tap. Even though the direct action of the haematoma does not completely arrest the flow of blood through the superior longitudinal sinus, as can be seen on all the angiograms in the venous phase, it cannot be excluded with certainty that venous stasis due in some degree to reduced transit of blood in the sinus may play an important role in the determination of intracranial hypertension and therefore of headache (Iwata, 1964).

Both Stevenson et al. (1964) and Alexander (1961) were able to demonstrate a slowing down of cerebral circulation in their patients. It is very likely that both factors - that is, size of the haematoma and diminished reabsorption of cerebrospinal fluid due to venous stasis, are responsible for the increased intracranial pressure and therefore for the severe headache complained of by all patients.

It is a surprising fact that unilateral-less frequently bilateral, as reported by Columella et al. (1959), by Alexander (1961), and by Da Pian et al. (1963) - pyramidal signs occur equally in both upper and lower limbs. No patient presented an isolated lower limb weakness, while the first case in Columella's series (Columella et al., 1959) showed only upper limb paresis. Peripapillar oedema with venous engorgement completes the clinical picture. Both Alexander (1961) and Hooper (1959) observed patients with unequal pupils; papilloedema was observed to have developed a few hours after the accident (Alexander's Case 1), a few days later (five days after the accident in Case 1 of Columella et al.), and even a few weeks after (Stevenson et al., 1964). Nuchal rigidity was observed by Columella et al.
(1959), by Alexander (1961), and by Iwata (1964); and decerebrate posturing by Alexander (1961). Deficits of other cranial nerves were not observed, with the exception of abducens weakness by Stevenson et al. (1964).

The clinical course and prognosis of epidural haematomas at the vertex differ from those of other epidural haematomas, the former being more chronic and the latter favourable to the point of spontaneous recovery in a few cases (six out of 32) (Brodin, 1952; Columella et al., 1959; Lindgren, 1960; Alexander, 1961; Da Pian et al., 1963), with control angiographies showing a return to normal of the intracranial vascular pattern.

Indications for surgical intervention were in all cases on the basis of the size of the haematoma, and of the severity and progression of clinical signs. No patient with a small haematoma and with progressive improvement was operated upon. All patients survived.

The impression gathered from the literature is that knowledge of epidural haematomas at the vertex is still scanty. These haematomas are rarely described as specific pathological entities. It is for this reason that it was thought worthwhile to report a single new case.

\section{SUMMARY}

A critical survey is made of the literature on extradural haematomas 'at the vertex'. As the present state of knowledge seems to be still rather fragmentary, a new case is described in detail.

\section{REFERENCES}

Alexander, G. L. (1961). Extradural haematoma at the vertex. $J$. Neurol. Neurosurg. Psychiat., 24, 381-384.

Brodin, H. (1952). Extradural hematomas. (A survey of cases covering a 20-year period with special reference to diagnosis.) Acta chir. scand., 102, 99-109.

Columella, F., Delzanno, G. B., and Nicola, G. C. (1959). L'ematoma epidurale al vertice. Sist. nerv., 2, 104-118.

D'Andrea, F., and Conforti, P. (1959). Considerazioni cliniche sull'ematoma epidurale 'al vertice'. Osped. psichiat., 27, 25-38.

Da Pian, R., Benati, A., Bricolo, A., Tomasi, A., Perbellini, D., and Dalle Ore, G. (1963). Ematomi extradurali traumatici del terzo medio del seno longitudinale superiore. Osped. Ital.-Chir., 8, 667-676.

Da Rocha-Melo, A., and Resende, J. (1959). Dois casos de hematoma extradural cronico. Rev. esp. Oto-neuro-oftal., 18, 166-169.

Guthrie, G. J. (1862). Commentaries on the Surgery of the War in Portugal, Spain, France, and the Netherlands, from the Battle of Rolica, in 1808, to that of Waterloo, in 1815; with Additions Relating to those in the Crimean in 1854-1855. Showing the Improvements made During and Since that Period in the Great Art and Science of Surgery and All the Subjects to which they Relate. 6th ed., p. 349. J. B. Lippincott, Philadelphia.

Hooper, R. (1959). Observations on extradural haemorrhage. Brit. J. Surg., 47, 71-87.

Iwata, K. (1964). Sagittal sinus hematoma. (Angiographic demonstration and clinical pathology.) Pac. Med. Surg., 72, 340-342.

Lindgren, S. O. (1960). Acute severe head injuries. Acta chir. scand., Suppl. No. 254, 1-49. 
McKissock, W., Taylor, J. C., Bloom, W. H., and Till, K. (1960). Extradural haematoma. (Observations on 125 cases.) Lancet, 2, 167-172.

Pecker, J., Javalet, A., and Stabert, C. (1959). L'angiographie dans les traumatismes craniens. $J$. Radiol. electrol., 40, 623-638.

Raaf, J. (1948). Massive extradural hematoma. Amer. J. Surg., 76, 567-577.

Reichert, F. L., and Morissey, E. J. (1941). Extradural venous hemorrhage. Ann. Surg., 113, 204-208.

Rowbotham, G. F. (1949). Acute Injuries of the Head. Their Diagnosis, Treatment, Complications and Sequels. 3rd ed. Livingstone, Edinburgh.
Schechter, M. M. (1966). Angiography in head trauma. Clin. Neurosurg., 12, 193-225.

Stevenson, G. C., Brown, H. A., and Hoyt, W. F. (1964). Chronic venous epidural hematoma at the vertex. J. Neurosurg., 21, 887-891.

Tiwisina, T., and Stäcker, A. (1959). Die frischen Schädel Hirnverletzungen im Gefässbild. Chirurg., 30, 344-349.

Wertheimer, P., Levy, A., Laplas, C., and Tusini, G. (1958). Les aspects angiographiques des épanchements intracraniens traumatiques. Lyon chir., 54, 481-493.

Wickbom, I. (1948). Angiography of the carotid artery. Acta radiol. (Stockh.), Suppl. No. LXXII, 1-141. 